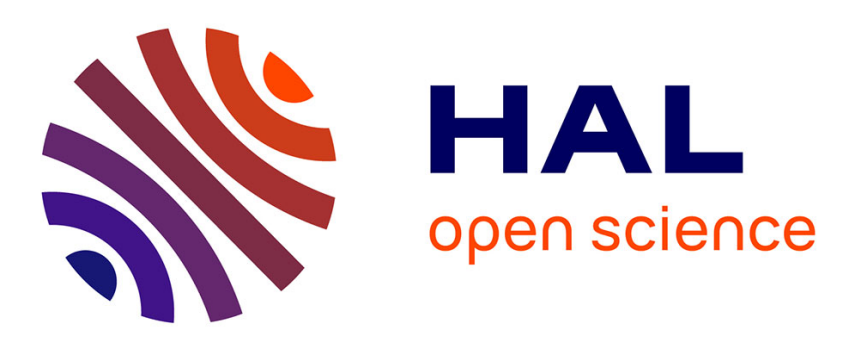

\title{
150-million-year-old sea spiders (Pycnogonida: Pantopoda) of Solnhofen
}

Romain Sabroux, Denis Audo, Sylvain Charbonnier, Laure Corbari, Alexandre Hassanin

\section{- To cite this version:}

Romain Sabroux, Denis Audo, Sylvain Charbonnier, Laure Corbari, Alexandre Hassanin. 150-millionyear-old sea spiders (Pycnogonida: Pantopoda) of Solnhofen. Journal of Systematic Palaeontology, 2019, 17 (22), pp.1927-1938. 10.1080/14772019.2019.1571534 . hal-02417296

\section{HAL Id: hal-02417296 https: / hal.sorbonne-universite.fr/hal-02417296}

Submitted on 18 Dec 2019

HAL is a multi-disciplinary open access archive for the deposit and dissemination of scientific research documents, whether they are published or not. The documents may come from teaching and research institutions in France or abroad, or from public or private research centers.
L'archive ouverte pluridisciplinaire HAL, est destinée au dépôt et à la diffusion de documents scientifiques de niveau recherche, publiés ou non, émanant des établissements d'enseignement et de recherche français ou étrangers, des laboratoires publics ou privés. 


\section{0-million-year-old sea spiders (Pycnogonida: Pantopoda) of Solnhofen}

Journal of Systematic Palaeontology

Romain Sabroux ${ }^{1 *}$, Denis Audo ${ }^{2,3}$, Sylvain Charbonnier ${ }^{4}$, Laure Corbari ${ }^{1}$, Alexandre Hassanin $^{1}$

${ }^{1}$ Institut de Systématique Évolution Biodiversité (ISYEB, UMR 7205), Muséum national d'Histoire naturelle, CNRS, Sorbonne Université, EPHE, 57 rue Cuvier, CP 51, 75005 Paris, France.

${ }^{2}$ Yunnan Key Laboratory for Palaeobiology, Yunnan University, China

${ }^{3}$ MEC International Joint Laboratory for Palaeobiology and Palaeoenvironment, Yunnan University, China

${ }^{4}$ Centre de Recherche sur la Paléobiodiversité et les Paléoenvironnements (CR2P, UMR 7207), Muséum national d’Histoire naturelle, Sorbonne Université, MNHN, CNRS, 57 rue Cuvier, CP 38, 75005 Paris, France.

*Corresponding author: romain.sabroux@mnhn.fr 


\section{Abstract}

Sea spiders (Pycnogonida) are strange arthropods characterized by a unique morphology, including reduced body, egg-carrying appendages, and a proboscis. This peculiar body plan dates at least as early as the first undoubted occurrence of the group, 425 million years ago in the Silurian. All extant species belong to the order Pantopoda, characterized by cylindrical legs and an unsegmented abdomen. Paleozoic fossils are much more diversified, and exhibit features very different from pantopod morphology such as a segmented abdomen, limbs specialized to swim, or even a flagellum. The few Mesozoic fossils from the single Jurassic palaeoenvironment of La Voulte-sur-Rhône (south-eastern France) instead have strong affinities to Pantopoda.

Here, we investigate the morphology of nine sea spider fossils using a new photographic protocol to document morphology, combining focus stacking and differential colorization. We also describe two new species of fossil pycnogonids from the Late Jurassic of Solnhofen (southern Germany): Colossopantopodus nanus n. sp. is closely allied to a large species from La Voulte-sur-Rhône, but distinct in its smaller size; the other, ?Eurycyde golem n. sp., is the first known fossil representative of the extant family Ascorhynchidae. Seven additional specimens, too poorly preserved for taxonomic description, are illustrated. The comparisons reveal that the shallow lagoons of Solnhofen contained a diverse assemblage of pantopods. Altogether with the fauna of La Voulte-sur-Rhône, the results suggest that Pantopoda became the dominant pycnogonid taxon of both deep and shallow marine waters after the Jurassic.

Keywords: Pycnogonida - Ascorhynchidae - Colossendeidae - Late Jurassic - Solnhofen Konservat-Lagerstätte 


\section{Introduction}

Sea spiders (Arthropoda: Pycnogonida) represent c. 1,400 extant species, occurring in all marine environments at all depths (Bamber et al. 2018). Their fossil record (fig. 1) is known at least as early as the Late Silurian (c. $425 \mathrm{Ma}$ ) (Siveter et al. 2004) but could date back to the Late Ordovician (c. $450 \mathrm{Ma}$ ) (Rudkin et al. 2013) or Late Cambrian (c. $500 \mathrm{Ma}$ ) (Waloszek \& Dunlop 2002). Sea spiders are considered to be an early offshoot of chelicerates (sister-group of Euchelicerata, i.e. horseshoe crabs and arachnids) (Brusca \& Brusca 2003; Regier et al. 2010) but are treated as a separate subphylum of arthropods by some authors (e.g. Hedgpeth 1948; Dunlop \& Arango 2005).

Extant pycnogonids are morphologically quite diverse, with variation in the number of appendages, including walking legs (from 8 to 12) and cephalic appendages - an uncommon trait among arthropods. They also possess several highly derived morphological characters; walking legs containing part of the reproductive and digestive systems, proboscis for suction feeding, reduction and loss of segmentation of the abdomen. Besides, in most of families, males take care of the fertilized eggs on their specialized ovigerous legs (Arnaud \& Bamber 1987). All extant sea spiders belong to the order Pantopoda Gerstäcker, 1863, a group of benthic crawlers, rather weak swimmers, and generally predators of sessile and slow-moving metazoans (e.g. cnidarians, bryozoans, molluscs, echinoderms) (Dietz et al. 2018).

Paleozoic sea spiders exhibit even higher morphological diversity. The Early Devonian species of the Hunsrück slate (c. 400 Ma; Germany) are the most remarkable example, since they present a large array of morphologies in a single environment (fig. 1) from the flatlegged swimming sea spiders, like Palaeoisopus problematicus Broili, 1928, to long-legged walkers, like Palaeopantopus maucheri Broili, 1929, and Flagellopantopus blocki Poschmann \& Dunlop, 2006. Pentapantopus vogteli Kühl, Poschmann \& Rust, 2013, may have the characteristic reduced abdomen of extant fauna, whereas $P$. problematicus and $P$. maucheri 
exhibit respectively a 5- and 3-segmented abdomen. Flagellopantopus blocki bears a long caudal flagellum. Finally, $P$. problematicus was large, up to $40 \mathrm{~cm}$ of leg-span, while Palaeothea devonica Bergström, Stürmer \& Winter, 1980, did not exceed one centimetre (Bergström et al. 1980; Poschmann \& Dunlop 2006; Kühl et al. 2013). Some of those original morphological features, including paddling legs, are shown in the older Haliestes dasos Siveter, Sutton, Briggs \& Siveter, 2004, from the Lower Silurian Herefordshire Lagerstätte (c. 425 Ma; United Kingdom) (Siveter et al. 2004). Palaeomarachne granulata Rudkin, Cuggy, Young \& Thompson, 2013, which is probably a pycnogonid moult from the Upper Ordovician William Lake Lagerstätte (c. 450 Ma; Manitoba, Canada), is distinct due to the serial segmentation of its head (Rudkin et al. 2013). Paleozoic pycnogonids have been assigned to up to three fossil-specific orders (Bamber 2007), and possible affinities to Pantopoda have been suggested only for three Devonian species (F. blocki, P. devonica, $P$. vogteli) (Bergström et al. 1980; Bamber 2007; Kühl et al. 2013). After a hiatus of about 250 Ma between Early Devonian and Middle Jurassic (fig. 1), this morphologic diversity vanishes: the three Mesozoic species from the palaeoenvironment of La Voulte-sur-Rhône Lagerstätte (Callovian: c. $165 \mathrm{Ma}$ ) are all Pantopoda, strikingly close to the three extant families Ammotheidae Dohrn, 1881, Colossendeidae Jarzynsky, 1870, and Endeidae Norman, 1908 (Bamber 2007; Charbonnier et al. 2007a, b). These fossils are thought to be remnants of a deep-sea fauna (Charbonnier et al. 2007a, b; Charbonnier 2009).

The Late Jurassic of Solnhofen (southern Germany) (c. 150 Ma) yielded several fossils originally described as sea spiders: Pentapalaeopycnon inconspicua Hedgpeth, 1978; Phalangites priscus Münster, 1836 and Pycnogonites uncinatus Quenstedt, 1852. These were, however, fragmentarily preserved phyllosomes (achelate lobster larvae) (Polz 1969; Bergström et al. 1980), as suggested by their biramous appendages (maxillipeds 3, legs 1, 2, 3 ), slender $4^{\text {th }}$ pair of legs (the fifth pair of legs in fossils erroneously interpreted as sea 
spiders), and leaf-like thorax (see for example Hedgpeth 1978). More recently, other fossils of sea spider have been reported (cited in Waloszek \& Dunlop 2002; pictured in Dunlop \& Bechly 2015), but the granularity of the limestone casts doubts on the identification for formal description (J. Dunlop personal communication 2009). In the present study, we used photographic techniques highlighting the 2-dimensional shape of fossils to examine the morphology of nine specimens and describe two new species from Late Jurassic Solnhofentype outcrops.

\section{Material and methods}

\section{Material}

Our study is based on nine fossil specimens, of which five are housed in the Jura-Museum Eichstätt (Bavaria, Germany): JME-SOS-2086, 3652, 3660, 6290, 6291a; three in the Staatliches Museum für Naturkunde Stuttgart (Baden-Württemberg, Germany): SMNS70156, 70209, 70402; one in the Natural History Museum (London, United Kingdom): NHMUK-In-39751. All specimens except JME-SOS-2086 were studied directly; the latter was studied from a good quality cast of the original fossil provided by the Jura-Museum Eichstätt.

The specimens come from the lithographic limestones cropping out in the vicinity of the Solnhofen-Eichstätt area. However, the exact quarries where the nine specimens were discovered were not recorded. All specimens are preserved slightly flattened in a micritic limestone. In seven specimens, the fossils have the same colour and texture as the surrounding sediment and do not exhibit visible auto-fluorescence under UV light. By contrast, the specimen JME-SOS 6291a presents small traces of preserved proboscis cuticle or tissue. In most cases, it seems that the original body was lost during fossilisation, and that only the shape was preserved as an imprint. Specimens are preserved in either dorsal or ventral view, generally subcomplete, although some sections of appendages or of the body may be missing 
or eroded, probably lost while opening the limestone. Specimen JME-SOS 3660 and SMNS70156 are preserved associated with remains of comatules (swimming crinoids) (supplementary material 1).

\section{Methods}

The specimens were documented using macrophotographic techniques. All images were generated using focus-stacking to provide a final image with an increased depth of field. Fluorescence imaging was attempted under UV, then blue-green light to search for traces of fluorescence linked to fossilized tissues (Haug \& Haug 2011; Haug et al. 2011; Kerp \& Bomfleur 2011), both without result. Contrast was enhanced by cross-polarized light imaging, with a cropped light source, to reveal surfaces and avoid strong reflections (Bengston 2000; Haug et al. 2011; Kerp \& Bomfleur 2011). Images were taken with various orientations of the light to reveal the various anatomic details. Finally, a microtopographical map (fig. 2B; 3B) of the specimen was realised: this was achieved by taking several pictures with deliberate shallow depth of field, desaturating each image, sequentially colouring each picture with a different tint, combining pictures in an image stacker program (Zerene stacker@), Depth map, stacking algorithm). The final image displays colours related to the distance of the item from the camera, revealing hence, the volume of the specimen. For this reason, the specimen has to lay as parallel as possible to the camera to minimize background shift in colours. Note that the original files can also be used to produce a natural light image stack. Similar techniques have been used in neuroanatomy (Castano et al. 1995, Mayer et al. 2010) and to visualize muscle tissue based on confocal microscopy images (Schmidt-Rhaesa \& Kulessa 2007). However, as far as we are aware, it has not yet been used to study the surface of opaque fossils. This technique can be used as a complement to stereophotography (supplementary material 2) in order to detect structures preserved in volume directly.

\section{Systematic palaeontology}


All studied fossils are assigned to Pycnogonida based upon the presence of a proboscis (however not clearly identified in JME-SOS 3660) and ovigers (however not spotted in JMESOS 3652). The absence of biramous appendages (all eight-legged) and the "sea-spider-like" body-shape (slender body and orientation of the articles of the slender legs; however, the trunk is not visible in JME-SOS-3652) rules out confusion with phyllosomes. Affinities to Pantopoda are evident by the simple lateral processes and cylindrical legs with elongate podomeres (femorae and tibiae 1 and 2 in extant species, i.e. fourth, fifth and sixth articles). The abdomen is generally poorly preserved or not preserved at all, but the observable examples are short, suggesting, again, affinities to Pantopoda. Two of the fossils are preserved enough to enable their formal description (hereafter); others (supplementary material 1) are too poorly preserved to be identified further, and their state does not permit relevant description nor grouping in distinct morphotypes. One specimen is, however, discussed in supplementary material 1.

Class Pycnogonida Latreille, 1810

Order Pantopoda Gerstäcker, 1863

Family Ascorhynchidae Hoek, 1881

Genus Eurycyde Schiödte, 1857

Type species. Eurycyde hispida (Krøyer, 1844) by monotypy.

Diagnosis (Hedgpeth 1948; Child 1992). Trunk segments with flaring posterior rims, without median tubercles; lateral processes separated by less than their own diameters, with slender dorsodistal and sometimes laterodistal tubercles. Ocular tubercle moderately long. Proboscis pyriform, carried ventrally at the tip of a cylindrical petiole extending from the head. Abdomen moderately long, with dorsal field of stout spines. Chelifore scapes 2-segmented, 
slender, with long dorsal spines; chelae tiny, vestigial. Palps 9-segmented. Ovigers 10segmented, with strong strigilis bearing many denticulate spines and terminal claw. Legs with long tubular spines, some bearing lateral setules; propodus (eight leg podomere) without heel or heel spines; auxiliary claw absent.

?Eurycyde golem n. sp.

(Fig. 2A, B, C; supplementary material 2)

Material examined. holotype NHMUK-In-39751

Diagnosis. Trunk four-segmented, with four pairs of walking legs; thickened posterior margin of each trunk segment, lateral processes simple, distance from each other equal to their own diameter, lateral extensions of head directly lateral to ocular tubercle. Proboscis pyriform, inserted at extremity of an unobserved structure. Chelifores present. Palps present. Ovigers present.

Derivation of name. The specific epithet refers to the Golem, creature of Hebraic folklore, in reference to the mineral and ancient nature of the fossil compared to other species of the genus.

Description. Trunk robust (length: $4.5 \mathrm{~mm}$ ), segmented into four metameres with posterior margin thickening (cephalosoma length: $1.8 \mathrm{~mm}$; second trunk segment: $0.9 \mathrm{~mm}$; third trunk segment: $1.1 \mathrm{~mm}$; fourth trunk segment: $0.8 \mathrm{~mm}$ ). First tagma (cephalosoma) formed by conjoined head and first pediferous segment. Cephalosoma bearing ocular tubercle of unknown height, central depression possibly representing remains of lumen, suggesting it broke. Head assumed with a short pre-ocular neck (extension of the head before the ocular tubercle). No dorsomedian tubercle on the trunk. Lateral processes (i.e. lateral extension of the trunk, on which legs articulate) without annular swelling, and the distance from each other equal to their own diameter. Two different structures can be interpreted as abdomen (fig. 2C): 
(i) laterally-compressed structure on left fourth lateral process: straight, of medium size, and without visible trace of articulation with trunk; alternatively, it could be a deformation of the lateral process (ii) rough shape visible posterior to last trunk segment: of medium size, slightly bent, apparently articulated on last trunk segment; alternatively, it could be an artefact from the substrate.

Visible part of proboscis pyriform, extending anterior to the head, bent ventrally in type specimen. Length: $3.9 \mathrm{~mm}$.

Chelifores present, insertion not visible. Chelae missing or not preserved, degree of development unknown. Scapes assumed two-articulated.

Traces of assumed palps, long, directed anteriorly on type specimen.

Traces of one assumed oviger, most of it hidden on ventral side in type specimen. Lateral extension of head adjacent to ocular tubercle, with tall, flattened dorsal tubercle.

Legs cylindrical with indistinct articulations. First right leg length: 12.4 mm (hypothetic lateral process excluded).

Remarks. ?Eurycyde golem n. sp. (fig 2 a, b, c) shows similarities with extant Ascorhynchidae: pyriform, very movable proboscis; lateral head extension (corresponding in extant species to oviger insertion); presence of chelifores without developed chelae. The basis of the ventrally folded proboscis is far from the ocular tubercle, suggesting it is inserted at the end of an anterior structure. This character excludes other Ammotheidae except Dromedopycnon Child, 1982, and Hedgpethius Child, 1974. However, these two latter genera do not show lateral head extensions. The structure on which the proboscis inserts is poorly preserved and perhaps broken. It is therefore not possible to identify it confidently: it can be either a pre-ocular neck, i.e. an anterior extension of the head, as in several species of Ascorhynchus Sars, 1877; or a petiole which is articulated on the head at its basis, as in 
Eurycyde (fig. 2D, E, F). Additional characters, however, give clues to the taxonomic affinities of the fossil: the long chelifores and the pre-ocular neck not reaching the base of the proboscis support placement in Eurycyde, even though this interpretation (fig. 2C) remains ambiguous considering the preservation. Furthermore, the position of the proboscis, with the broadest part positioned anteriorly, fits more with Eurycyde than Ascorhynchus. In Ascorhynchus, the basis of the proboscis is narrow and inserted ventrally, and therefore would be hidden under the tip of the preocular neck in a similar position. For this reason, we prefer placement in Eurycyde.

Other characters are in agreement with Eurycyde (but do not exclude Ascorhynchus): tubercle on the lateral head extensions; enlargement of posterior margins of the trunk, without dorsal tubercle; slight distance between lateral processes (no more than their own diameter). ?Eurycyde golem is much larger than extant Eurycyde species (about $20 \mathrm{~mm}$ of legspan i.e. twice the maximum for extant species) (fig. 2A, D). In our interpretation, the head exhibits a short pre-ocular neck, similar to E. arctica Child, 1995; E. antarctica Child, 1987; E. depressa Child, 1995; and E. muricata Child, 1995.

Family Colossendeidae Jarzinsky, 1870

Genus Colossopantopodus Charbonnier, Vannier \& Riou, 2007

Type species. Colossopantopodus boissinensis Charbonnier, Vannier \& Riou, 2007, by original designation

Emended diagnosis (Charbonnier et al. 2007b). Trunk segmented; four pairs of mediumsized walking legs; long to very long sub-cylindrical proboscis; long ovigers originating ventrally; chelifores absent or not preserved, abdomen unknown.

\section{Colossopantopodus nanus n. sp.}

(Fig. 3 A, B, C; supplementary material 2) 
Material examined: holotype JME-SOS-6291a

Diagnosis. Distinctly smaller than type species. Trunk segmented, with four pairs of walking legs; lateral processes simple, separated from each other by less than their diameter. Proboscis long, slender, cylindrical. Chelifores absent or not preserved. Ovigers present.

Derivation name. The specific epithet nanus (from latin): “dwarf”, emphasizes the small size of the species compared to Colossopantopodus boissinensis.

Description. Large size: trunk (length: $15.1 \mathrm{~mm}$ ) rather slender, with signs of segmentation at least between second and third, and third and fourth segments (second and third trunk segments: $4.6 \mathrm{~mm}$; fourth trunk segment: $1.2 \mathrm{~mm}$ ?). Lateral processes without annular swelling, separated by less than their diameter. Possible abdomen identified caudally, very short.

Proboscis long, slender, cylindrical (length: $14.9 \mathrm{~mm}$ ), with signs of median and distal swelling.

Chelifores absent or not preserved.

Assumed palps shorter than the proboscis.

Ovigers present, originating ventrally from large protuberance than may be a podomere or a body extension. Structure of ovigers unclear, strigilis strong.

Legs cylindrical with indistinct articulations, of medium size. First right leg length: $41.6 \mathrm{~mm}$ ?

Remarks. The ventral knobs behind the head (fig. 3A, B, C) are interpreted as the head extensions at the base of the ovigers. Their medioventral position suggests affinities to Colossendeidae (fig. 3F) together with the very long, slender shape of the ovigers and their large size (fig. 3 C, D, E, F). Furthermore, the examined specimen shows affinities to the subfamily Colossendeinae Hoek, 1881 (Fam. Colossendeidae) due to the shape of the long, 
straight, cylindrical proboscis. The legs are short and thick for the family, comparable to “stout” Colossendeis (e.g. C. proboscidea (Sabine, 1824), C. robusta Hoek, 1881); the trunk is (fully?) segmented, as in C. articulata Loman, 1908, or Pentacolossendeis reticulata Hedgpeth, 1943, but contrary to the latter, C. nanus has four pairs of legs. Those characters are shared with $C$. boissinensis, however trunk segmentation was not originally reported in its original description (Charbonnier et al. 2007b). Strong evidence for the presence of palps is still lacking to consider Colossopantopodus as a synonym of Colossendeis.

Colossopantopodus boissinensis differs from C. nanus in the comparable characters only by its larger size (trunk size 1.34 times bigger than C. nanus). Therefore, we cannot rule out that they are synonyms, representing different ontogenic stages of the same species (although life cycle of colossendeids is completely unknown). In extant taxa, species identification relies on characters unlikely to be preserved in Solnhofen fossils, as palp articulation, or proboscis bending.

\section{Discussion}

\section{Palaeoecology and palaeobiology}

During the Late Jurassic, Europe resembled a vast archipelago with numerous reefs and shallow lagoons (Thierry 2000). Solnhofen lagoons were not deeper than 30 to $60 \mathrm{~m}$ (Barthel et al. 1990), whereas La Voulte-sur-Rhône was a deep marine palaeoenvironment (aphotic or dysphotic) (Charbonnier et al. 2007a, b; Charbonnier 2009). As Solnhofen lagoons were quite far from the sea, their bottom waters may have been, in many cases, anoxic or hypersaline and therefore hostile to life (Barthel et al. 1990; Viohl 1996). However, moults or resting trace suggest that, in some cases, a few lagoons could have been inhabited by living animals, at least temporarily (Schweigert \& Dietl 2015). 
Due to these conditions, most sea spiders found in Solnhofen may not have lived on the bottom where they fossilized. As occasional swimmers (Arnaud \& Bamber 1987), sea spiders were likely to be flushed away from their living habitat into the bottom of the lagoon by rare storm events, as suggested for other Solnhofen fossils (Barthel et al. 1990). As has been suggested for fishes (Viohl 1996), they probably lived in nearby environments surrounding the anoxic or hypersaline bottom waters in the centre of lagoons: coral bioherms or shallowwater soft bottoms. It seems less likely that specimens came from the oceanic waters, which were distant, because of the fragility of sea spiders and comatulids accompanying them (supplementary material 1). Another possibility is that pycnogonids used driftwood as a substrate and fell onto the bottom at their death or by accident (small debris of driftwood was reported by Barthel et al. 1990).

The long, cylindrical legs of the pycnogonids described herein suggest they were epibenthic walkers like extant pantopods. Pycnogonids are generally grazing predators of sessile (e.g. actinians, bryozoans, poriferans) or slow-moving invertebrates (e.g. echinoderms, gastropods, annelids), and sometimes feed on minute arthropods, algae, or biofilms (Dietz et al. 2018). They use their proboscis to suck up their prey, or pieces of them. Extant species of Ascorhynchidae have been observed feeding on sponges or mollusks, and may also feed on soft corals (Dietz et al. 2018). Since their chelifores cannot reach the mouth at the tip of their very long and mobile proboscis, they probably feed on sessile prey which can be grazed without handling (Dietz et al. 2018). Therefore, ?Eurycyde golem n. sp. perhaps benefitted from sponge bioherms or coral reefs of Solnhofen lagoons (Barthel et al. 1990) as a walking substrate, as well as for food. Contrastingly, extant Colossendeidae are common on softbottoms (Müller 1993), so Colossopantopodus nanus n. sp. could have inhabited a different environment than ?E. golem n. sp., such as the few habitable lagoon bottoms (Schweigert \& Dietl 2015). Colossendeids have been observed preying on scyphozoans, anthozoans and 
hydroids, and limpets, and they may be also deposit feeders (Braby et al. 2009; Wicksten 2017; Dietz et al. 2018). The proboscis shape of Colossopantopodus nanus is rather short and cylindrical, like Colossendeis colossea (fig. 3A, B, C, E), which has been observed feeding on anthozoans (Braby et al. 2009). Anthozoans, scyphozoans and limpets were all present in the Solnhofen fauna (Barthel et al. 1990), providing a clue to the possible diet of C. nanus.

\section{Evolutionary history of Pantopoda among sea spiders}

Paleozoic sea spiders. Pantopoda is considered to be the only extant representative of Pycnogonida. Pantopoda is characterized by cylindrical walking legs with differently sized leg podomeres, unsegmented abdomen, and simple lateral processes (unarticulated nor striated) (Hedgpeth 1954, 1955; Bergström et al. 1980; Munilla 1999; Waloszek \& Dunlop 2002; Bamber 2007). De facto, three fossil species, Haliestes dasos, Palaeoisopus problematicus and Palaeopantopus maucheri, can be excluded from Pantopoda (Berström et al. 1980; Siveter et al. 2004). All three have a 3- to 5- segmented abdomen, and at least two had peculiar annular (articulated?) swelling at the base of the lateral processes, on which articulated legs. It is impossible to say if $H$. dasos has or not such swellings due to the resolution of its virtual reconstruction. Furthermore, $P$. problematicus and $H$. dasos exhibit flattened legs with sub-equal podomeres, which could be an adaptation to swimming (Berström et al. 1980; Siveter et al. 2004). Although Palaeomarachne granulata and Cambropycnogon klausmuelleri Waloszek \& Dunlop, 2002, do not offer many characters for comparison, the presence respectively of head serial segmentation (Rudkin et al. 2013), and gnathobases (also present in xiphosurans and trilobites) (Waloszek \& Dunlop 2002), which may be considered as plesiomorphic, suggest that they belong to early offshoots of Pycnogonida rather than Pantopoda.

Three other Paleozoic species, Flagellopantopus blocki, Pentapantopus vogteli, and Palaeothea devonica must be discussed further, as they have been considered as "modern” by 
several authors or have even been assigned to Pantopoda (Bergström et al. 1980; Bamber 2007; Kühl et al. 2013).

(i) Flagellopantopus blocki has been considered as Pantopoda incertae sedis by Bamber (2007), due to its cylindrical legs with differently sized podomeres and simple lateral processes. Poschmann \& Dunlop (2006) described a very different leg structure from extant species, but we suggest rather that they misinterpreted the coxae 1, 2, 3 (first, second, and third leg podomeres) as femorae, therefore shifting the following podomeres (supplementary material 3). Our new interpretation fits with classical cylindrical legs of sea spiders, however the podomeres formerly interpreted as coxae 1, 2, 3 should be interpreted as lateral processes, which show traces of annular swellings. Furthermore, the abdomen is segmented in two or three segments, suggesting close affinities to P. maucheri rather than to Pantopoda.

(ii) Pentapantopus vogteli was “modern-like” according to its descriptors (Kühl et al. 2013), due to its ten legs, which are only found among the extant fauna. But this is not a strong argument: there are only nine extant “polymerous” species (with 5/6 pairs of legs), dispatched in three highly diversified families (Colossendeidae Jarzynsky, 1870, Nymphonidae Wilson, 1878 and Pycnogonidae Wilson, 1878). Since legs have a role in respiration (Woods et al. 2017), additional pairs of legs may have been acquired independently by convergent adaptation. Furthermore, the most distal podomeres of legs are sub-equal and probably flattened, leading Kühl et al. (2013) to suggest affinities to H. dasos and/or P. problematicus. Traces of potential annular swellings are also visible. However, Kühl et al. (2013) described a small abdomen which, if accurately identified, is shared with Pantopoda. Such a combination of characters would have important consequences for our understanding of Pycnogonida evolution, however, this identification could be inaccurate, as other segmented structures around the so-called abdomen could be interpreted similarly. 
(iii) Palaeothea devonica shows a general “modern” outline, with cylindrical legs, probably vestigial chelae (like ammotheids and ascorhynchids) and dorsomedian tubercles (Bergström et al. 1980); but it is not possible to say whether the abdomen was segmented or not. Therefore, $P$. devonica could be the sole Pantopoda known from Paleozoic, although further investigation of its morphology has to be performed to confirm this view. Then, until Devonian at least, Pantopoda, if present, would have lived along with representatives of other Pycnogonida lineages.

Mesozoic diversification. All Mesozoic species (fig. 1) exhibit a typical Pantopoda morphology. Affinities of La Voulte-sur-Rhône species to extant fauna have already been acknowledged (Charbonnier et al. 2007b): Palaepycnogonides gracilis Charbonnier, Vannier \& Riou, 2007, to Ammotheidae (or Pycnogonidae); Colossopantopodus boissinensis Charbonnier, Vannier \& Riou, 2007, to Colossendeidae (fig. 3D, E, F); Palaeoendeis elmii Charbonnier, Vannier \& Riou, 2007, to Endeidae. Bamber (2007) interpreted them all as representatives of Endeidae, based upon the absence of chelifores and palps; however, the absence of the fragile cephalic appendages in fossils could be explained by a taphonomic bias (Charbonnier et al. 2007b). Conversely, C. boissinensis (fig. 3D) has two ventral knobs at the base of the proboscis, that can be interpreted as palp insertion and/or first podomere (fig. 3F), together with elongate ovigers articulating on short ventral podomeres or head extensions, a small strigilis, and huge size. This excludes Endeidae but matches with Colossendeidae. Furthermore, $P$. gracilis shows vestigial chelifores, which exclude its placement in Endeidae, and support the original designation as Ammotheidae (but this does not match absence of palps) or Pycnogonidae. Although generally lacking, the monotypic genus Pycnopallene Stock, 1950 shows reduced chelifores; however, the true status of this poorly documented genus is highly problematic. Finally, Palaeoendeis elmii is very similar to extant species of Endeis (Fam. Endeidae); however, ovigers are needed to confirm this view. 
The nine Solnhofen fossils in this study are all attributed to Pantopoda, and two of them are assigned to already described genera: Colossopantopodus nanus n. sp. is a close relative of $C$. boissinensis from La Voulte-sur-Rhône, while ?Eurycyde golem n. sp. belongs to the extant family Ascorhynchidae. Seven additional poorly preserved fossils (supplementary data 1) show traces of different morphologies, suggesting existence of further diversity in Solnhofen. With the fossils of La Voulte-sur-Rhône (Charbonnier et al. 2007b), this indicates that the Jurassic faunae had strong affinities to extant Pantopoda families (four identified), showing that (i) Pantopoda were probably not limited to deep-sea environments and are the only representatives of Pycnogonida found in Jurassic records, so the transition from diversified Pycnogonida to an exclusive Pantopoda fauna may have already occurred; and that (ii) the diversification of Pantopoda in at least some extant families predates the Middle Jurassic. Pycnogonida is ancient, at least from the Early Silurian, if not Late Cambrian or before (Waloszek \& Dunlop 2002; Siveter et al. 2004; Rudkin et al. 2013). However, pantopods are very different from other arthropods regarding morphological and molecular data (Arango 2003; Dunlop \& Arango 2005; Arango \& Wheeler 2007; Nakamura et al. 2007; Sabroux et al. 2017). Inter-familial relationships are difficult to resolve, suggesting rapid diversification, i.e. radiation (Arabi et al. 2010). These are reasons to suspect that extant Pantopoda radiated from a relict lineage which underwent a bottleneck event. According to fossil records this took place between the Early Devonian and the Middle Jurassic. As the Permian-Triassic mass extinction, which marks the transition from Paleozoic to Mesozoic, precipitated among others the end of major marine arthropods lineages such as Trilobitomorpha (Lerosey-Aubril \& Feist 2012) and Eurypterida (Tetlie 2007), it is tempting to think that sea spider narrowly escaped the same fate. However, other events such as the Triassic-Jurassic extinction (Benton 1995), or the Toarcian anoxic event (e.g. Vörös 2002) also impacted the marine fauna during the 250 Ma hiatus and should not be underestimated. 


\section{Acknowledgments}

The authors thank Claire Mellish (Natural History Museum, London), Martina Kölbl-Elbert (Jura-Museum, Eichstätt) and Günter Schweigert (Staatliches Museum für Naturkunde, Stuttgart) for the access to fossil specimens. Günter Schweigert also helped to obtain several important publications. We are also grateful to Nalani Schnell (Muséum national d'Histoire naturelle, Paris), as Manon Delval and Didier Geffard-Kuriyama (UMS-MNHN-CNRS 2700) for pictures of extant specimens, and to Stéphane Hourdez (CNRS), Philippe Bouchet (MNHN) and the crew of the Planète Revisitée who provided them. The authors gratefully acknowledge Jason Dunlop (Museum für Naturkunde, Berlin) for his suggestions to improve the quality of the manuscript, and whose role has been determinant in the inclusion of the London specimen. Finally, we are indebted to Carrie Schweitzer and Rodney Feldmann (Kent State University), as the two anonymous reviewers for their insightful comments on earlier versions of the present manuscript.

\section{References}

Arabi, J., Cruaud, C., Couloux, A. \& Hassanin, A. 2010. Studying sources of incongruence in arthropod molecular phylogenies: sea spiders (Pycnogonida) as a case study. Comptes rendus biologies, 333(5), 438-453.

Arango, C. P. 2003. Molecular approach to the phylogenetics of sea spiders (Arthropoda: Pycnogonida) using partial sequences of nuclear ribosomal DNA. Molecular phylogenetics and evolution, 28(3), 588-600.

Arango, C. P. \& Wheeler, W. C. 2007. Phylogeny of the sea spiders (Arthropoda, Pycnogonida) based on direct optimization of six loci and morphology. Cladistics, 23(3), 255-293. 
Arnaud, F. \& Bamber, R. N. 1987. The biology of Pycnogonida. Advances in marine Biology, 24, 1-96.

Bamber, R. N. 2007. A holistic re-interpretation of the phylogeny of the Pycnogonida Latreille, 1810 (Arthropoda). Zootaxa, 1668, 295-312.

Bamber, R. N., El Nagar, A. \& Arango, C. 2018. Pycnobase: World Pycnogonida Database. Accessed at http://www.marinespecies.org/pycnobase accessed on 2018-05-28

Barthel, K. W., Swinburne, N. H. M. \& Morris, S. C. 1990. Solnhofen. A study in Mesozoic palaeontology. Cambridge University Press, Cambridge, 236 pp.

Bengtson, S. 2000. Teasing fossils out of shales with cameras and computers. Palaeontologia Electronica, 3(Art. 4), 1-14.

Benton, M. J. 1995. Diversification and extinction in the history of life. Science, 268(5207), $52-58$.

Bergström, J., Stürmer, W. \& Winter, G. 1980. Palaeoisopus, Palaeopantopus and Palaeothea, pycnogonid arthropods from the Lower Devonian Hunsrück Slate, West Germany. Paläontologische Zeitschrift, 54(1-2), 7-54.

Braby, C. E., Pearse, V. B., Bain, B. A. \& Vrijenhoek, R. C. 2009. Pycnogonid-cnidarian trophic interactions in the deep Monterey Submarine Canyon. Invertebrate biology, 128(4), 359-363.

Brusca, R. C. \& Brusca, G. J. 2003. Invertebrates second edition. Sinauer Associates, Sunderland, 936 pp.

Castano, P., Rumio, C., Morini, M., Miani, A. Jr. \& Castano, S. M. 1995. Threedimensional reconstruction of the Meissner corpuscle of man, after silver 
impregnation and immunofluorescence with PGP 9.5 antibodies using confocal scanning laser microscopy. Journal of Anatomy, 186, 261-270.

Charbonnier, S., Vannier, J., Gaillard, C., Bourseau, J. P. \& Hantzpergue, P. 2007a. The La Voulte Lagerstätte (Callovian): evidence for a deep water setting from sponge and crinoid communities. Palaeogeography, Palaeoclimatology, Palaeoecology, 250(1), 216-236.

Charbonnier, S., Vannier, J. \& Riou, B. 2007b. New sea spiders from the Jurassic La Voulte-sur-Rhône Lagerstätte. Proceedings of the Royal Society of London B: Biological Sciences, 274(1625), 2555-2561.

Charbonnier, S. 2009. Le Lagerstätte de La Voulte : un environnement bathyal au Jurassique. Mémoires du Muséum national d'Histoire naturelle, 199, 1-272.

Child, C.A. 1992 Shallow-water Pycnogonida of the Gulf of Mexico. Memoirs of the Hourglass Cruises, 9(1), 1-86.

Dietz, L., Dömel, J. S., Leese, F., Lehmann, T. \& Melzer, R. R. 2018. Feeding ecology in sea spiders (Arthropoda: Pycnogonida): what do we know? Frontiers in zoology, 15(1), 7.

Dunlop, J. A. \& Arango, C. P. 2005. Pycnogonid affinities: a review. Journal of Zoological Systematics and Evolutionary Research, 43(1), 8-21.

Dunlop, J. A. \& Bechly, G. 2015. Kieferklauenträger (Chelicarata). Pp. 292-298 in G. Arratia, H.-P. Schultze, H. Tischlinger, \& G. Viohl (eds) Solnhofen. Ein Fenster in die Jurazeit, 1, Dr. Frederich Pfeil, Munich.

Haug J.T. \& Haug C. 2011. Fossilien unter langwelligem Licht: Grün-Orange-Fluoreszenz an makroskopischen Objekten. Archaeopteryx, 29, 20-23. 


\section{Haug J. T., Haug C., Kutschera V. Mayer G., Maas A., Liebau S., Castellani C.,}

Wolfram U., Clarkson E. N. K. \& Waloszek D. 2011. Autofluorescence imaging, an excellent tool for comparative morphology. Journal of Microscopy, 244, 259-272.

Hedgpeth, J. W. 1948. The Pycnogonida of the Western North Atlantic and the Caribbean. Proceedings of the National Museum, 97(3216), 157-342.

Hedgpeth, J. W. 1954. On the phylogeny of the Pycnogonida. Acta Zoologica, 35(3), 193213.

Hedgpeth, J. W. 1955. Pycnogonida. Pp. 163-170. in R. C. MOORE (ed.). Treatise on invertebrate paleontology, Part P, Arthropoda 2. Geological Society of America, Boulder and University of Kansas Press, Lawrence, 181 pp.

Hedgpeth, J. W. 1978. A reappraisal of the Palaeopantopoda with description of a species from the Jurassic. Zoological Journal of the Linnean Society, 63(1-2), 23-34.

Kerp H. \& Bomfleur B. 2011. Photography of plant fossil - New techniques, old tricks. Review of Palaeobotany and Palynology, 166, 117-151.

Kühl, G., Poschmann, M. \& Rust, J. 2013. A ten-legged sea spider (Arthropoda: Pycnogonida) from the Lower Devonian Hunsrück Slate (Germany). Geological Magazine, 150(3), 556-564.

Lerosey-Aubril, R. \& Feist, R. 2012. Quantitative approach to diversity and decline in Late Palaeozoic trilobites. Pp. 535-555 in J. A. Talent (ed) Earth and Life. Springer, Dordrecht.

Mayer, G., Whittington, P. M., Sunnuck, P. \& Pflüger H.-J. 2010. A revision of brain composition in Onychophora (velvet worms) suggests that the tritocerebrum evolved in arthropods. BMC Evolutionary Biology, 10, 255. 
Müller, H. G. 1993. World catalogue and bibliography of the recent Pycnogonida. Wissenschaftlicher verlag, Wetzlar, 410 pp.

Munilla León, T. 1999. Evolución y filogenia de los picnogónidos. Pp. 273-279 in A. Melic, J. J. De Haro, M. Méndez \& Ribera (eds.). Evolución y filogenia de Arthropoda. Boletin de la Sociedad Entomológica Aragonesa, Zaragoza, 26, 1-806.

Nakamura, K., Kano, Y., Suzuki, N., Namatame, T. \& Kosaku, A. 2007. 18S rRNA phylogeny of sea spiders with emphasis on the position of Rhynchothoracidae. Marine Biology, 153(2), 213-223.

Polz, H. 1969 Beobachtungen an Pantopoden aus den Solnhofener Plattenkalken.Natur und Museum, 99(10), 457-467.

Poschmann, M. \& Dunlop, J. A. 2006. A new sea spider (Arthropoda: Pycnogonida) with a flagelliform telson from the Lower Devonian Hunsrück Slate, Germany. Palaeontology, 49(5), 983-989.

Regier, J. C., Shultz, J. W., Zwick, A., Hussey, A., Ball, B., Wetzer, R., Martin, J. W. \& Cunningham, C. W. 2010. Arthropod relationships revealed by phylogenomic analysis of nuclear protein-coding sequences. Nature, 463(7284), 1079.

Rudkin, D. M., Cuggy, M. B., Young, G. A. \& Thompson, D. P. 2013. An Ordovician Pycnogonid (Sea Spider) with Serially Subdivided 'Head'Region. Journal of Paleontology, 87(3), 395-405.

Sabroux, R., Corbari, L., Krapp, F., Bonillo, C., le Prieur, S. \& Hassanin, A. 2017. Biodiversity and phylogeny of Ammotheidae (Arthropoda: Pycnogonida). European Journal of Taxonomy, 286. 
Schmidt-Rhaesa, A. \& Kulessa, J. 2007. Muscular architecture of Milnesium tardigradum and Hypsibius sp. (Eutardigrada, Tardigrada) with some data on Ramazottius oberhaeuseri. Zoomorphology, 126, 265-281.

Siveter, D. J., Sutton, M. D., Briggs, D. E. \& Siveter, D. J. 2004. A Silurian sea spider. Nature, 431(7011), 978-980.

Schweigert, G. \& Dietl, G. 2015. Miscellanea aus dem Nusplinger Plattenkalk (OberKimmeridgium, Schwäbische Alb). 16. Die Ruhespur eines Eryoniden. Jahresberichte und Mitteilungen des Oberrheinischen Geologischen Vereins N.F., 97, 333-340.

Tetlie, O. E. 2007. Distribution and dispersal history of Eurypterida (Chelicerata). Palaeogeography, Palaeoclimatology, Palaeoecology, 252(3-4), 557-574.

Thierry, J. 2000. Early Kimmeridgian (146-144 Ma). Pp. 85-97 in S. Crasquin (ed.) Atlas Peri-Tethys, Palaeogeographical maps - Explanatory notes. CCGM/CGMW, Paris.

Vannier, J., Schoenemann, B., Gillot, T., Charbonnier, S., \& Clarkson, E. 2016. Exceptional preservation of eye structure in arthropod visual predators from the Middle Jurassic. Nature communications, 7, 10320.

Viohl, G. 1996. The paleoenvironment of the Late Jurassic fishes from the southern Franconian Alb (Bavaria, Germany). Pp. 513-528 in G. Arratia \& G. Viohl (eds) Mesozoic Fishes - Systematics and Paleoecology. Dr. Friedrich Pfeil, München.

Vörös, A. 2002. Victims of the Early Toarcian anoxic event: the radiation and extinction of Jurassic Koninckinidae (Brachiopoda). Lethaia, 35(4), 345-357. 
Waloszek, D. \& Dunlop, J. A. 2002. A larval sea spider (Arthropoda: Pycnogonida) from the Upper Cambrian “Orsten” of Sweden, and the phylogenetic position of pycnogonids. Palaeontology, 45(3), 421-446.

Wicksten, M. K. 2017. Feeding on cnidarians by giant pycnogonids (Pycnogonida: Colossendeidae Jarzinsky, 1870) in the North Central Pacific and North Atlantic oceans. The Journal of Crustacean Biology, 37(3), 359-360.

Woods, H. A., Lane, S. J., Shishido, C., Tobalske, B. W., Arango, C. P. \& Moran, A. L. 2017. Respiratory gut peristalsis by sea spiders. Current Biology, 27(13), R638R639. 
Figure 1. Fossil pycnogonids described in the literature (including this article), their origin, and the number of known specimens. Orsten, Sweden (Late Cambrian, c. $500 \mathrm{Ma}$ ), Cambropycnogon klausmuelleri Waloszek \& Dunlop, 2002 (larva), six specimens; William Lake Lagerstätte, Manitoba, Canada (Late Ordovician, c. 450 Ma), Palaeomarachne granulata Rudkin, Cuggy, Young \& Thompson, 2013, four specimens; Herefordshire (Early Silurian, c. 425 Ma), Haliestes dasos Siveter, Sutton, Briggs \& Siveter, 2004, one specimen; Hunsrück slate (Early Devonian, c. 400 Ma), Hu1: Palaeoisopus problematicus Broili, 1928, at least 57 specimens, Hu2: Palaeopantopus maucheri Broili, 1929, three specimens, Hu3: Palaeothea devonica Bergström, Stürmer \& Winter, 1980, one specimen, Hu4: Flagellopantopus blocki Poschmann \& Dunlop, 2006, one specimen, Hu5: Pentapantopus vogteli Kühl, Poschmann \& Rust, 2013, two specimens; La Voulte-sur-Rhône (Middle Jurassic, c. 160 Ma), V1: Colossopantopodus boissinensis Charbonnier, Vannier \& Riou, 2007, one specimen, V2: Palaeoendeis elmii Charbonnier, Vannier \& Riou, 2007, two specimens, V3: Palaeopycnogonides gracilis Charbonnier, Vannier \& Riou, 2007, c. 50 specimens; Solnhofen (Late Jurassic, c. 145 Ma), S1: ?Eurycyde golem n. sp., one specimen, S2: Colossopantopodus nanus n. sp., one specimen.

Figure 2. ?Eurycyde golem n. sp., holotype NHMUK-In-39751 (A, B, C), compared to the extant species Eurycyde raphiaster Loman, 1912 (MNHN-IU-2016-1178; đ̃, D, E, F). The fossil is shown under natural light with enhanced contrast (A) and in microtopographical map (B; see material and methods). The black arrows designate the proboscis, note that a slight tilt of the specimen translate into a lateral colour gradient on the matrix. The interpretative drawing (C) represents distinctively unambiguous shape (plain black lines), ambiguous or unclear structures (dashed black lines) and tentatively placed articulations (plain grey lines). General view of Eurycyde raphiaster (D) emphasis the similar structures identified on the 
fossil. The focus in dorsal view (E) shows the displacement of the proboscis on the left. The focus on the head in ventral view (F) reveals the petiole on which articulates the proboscis in living species. $a b$, abdomen; $c h$, chelifores; $c t$, cementary tubes; he, lateral head extension; $l 1$ 14, walking legs 1 to 4; ot, ocular tubercle; ov, ovigers; pa, palps; pe, petiole of the proboscis; pr, proboscis; t1-t4: trunk segments 1 to 4 . All scale bars 2 mm. Picture of fossil D.A; pictures of extant specimen and fossil interpretation R.S.

Figure 3. Colossopantopodus nanus n. sp., holotype JME-SOS-6291 (A, B, C), compared to Colossopantopodus boissinensis Charbonnier, Vannier \& Riou, 2007 (holotype MNHN.F.A52385; D) and the extant species Colossendeis australis Hodgson, 1907 (MNHNIU-2017-222; E, F; note the white parasitic bryozoans). The fossil is shown under natural light with enhanced contrast (A), and under microtopological map focusing on the base of ovigers (B; see material and method). Dashed lines in (A) and (B) indicate the base of the ovigers (see text for explanations). The interpretative drawing (C) represents distinctively unambiguous shape (plain black lines), ambiguous or unclear structures (dashed black lines) and tentatively placed articulations (plain grey lines). General views of Colossopantopodus boissinensis (D) and Colossendeis australis (E) emphasis the similar structures observed on C. nanus. The focus on forebody ventral view of Colossendeis australis (F) shows the ovigers insertion. l1-l4, walking legs 1 to 4; ob, oviger basis; ov, ovigers; $p a$, palps; $p b$, palp basis; $p r$, proboscis; $t 1$-t4: trunk segments 1 to 4 . All scale bars $5 \mathrm{~mm}$. Picture of $C$. nanus D.A.; picture of C. boissinensis S.C.; picture of extant specimen Manon Delval, Didier Geffard-Kuriyama \& R.S; fossil interpretation R.S. 


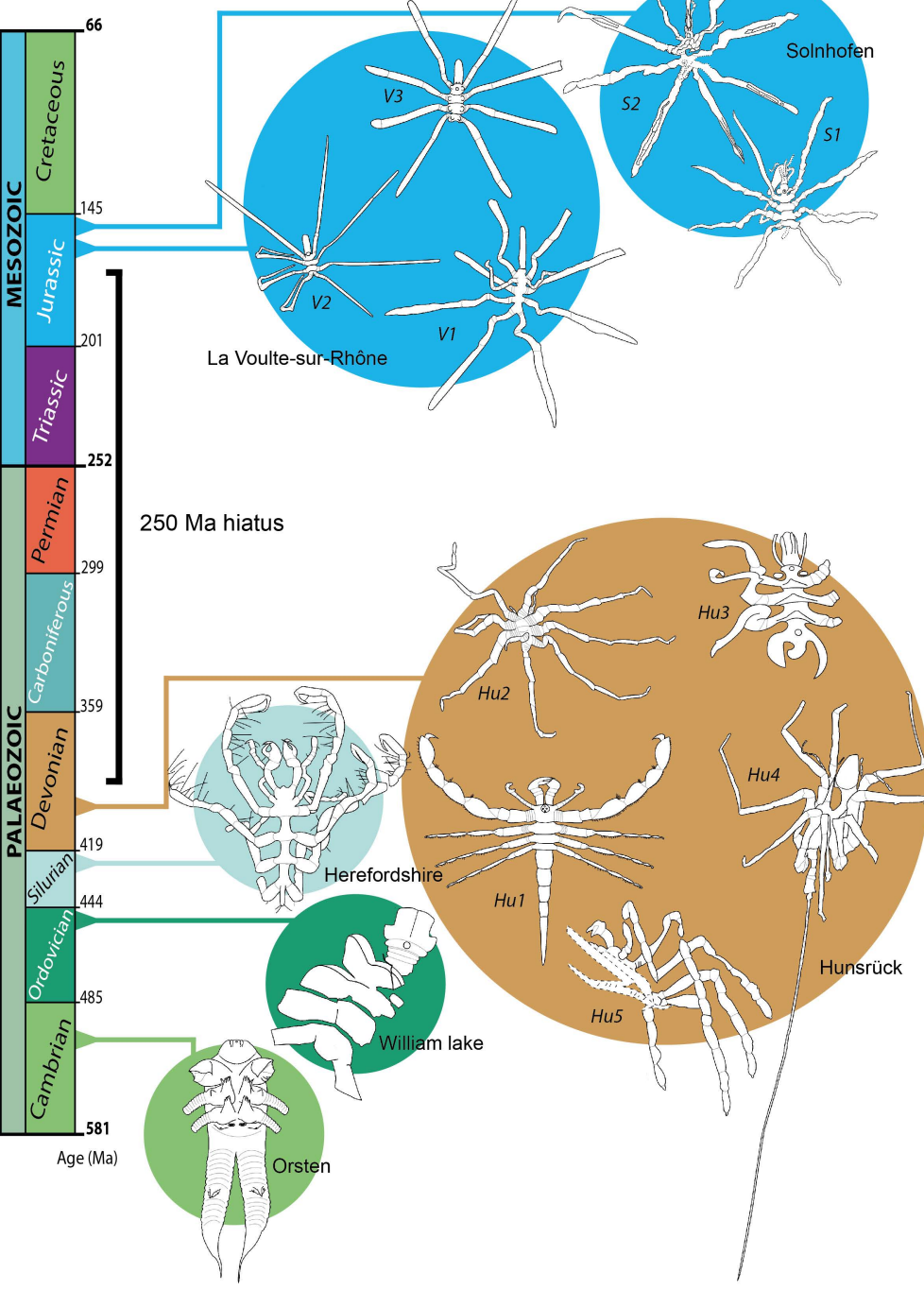




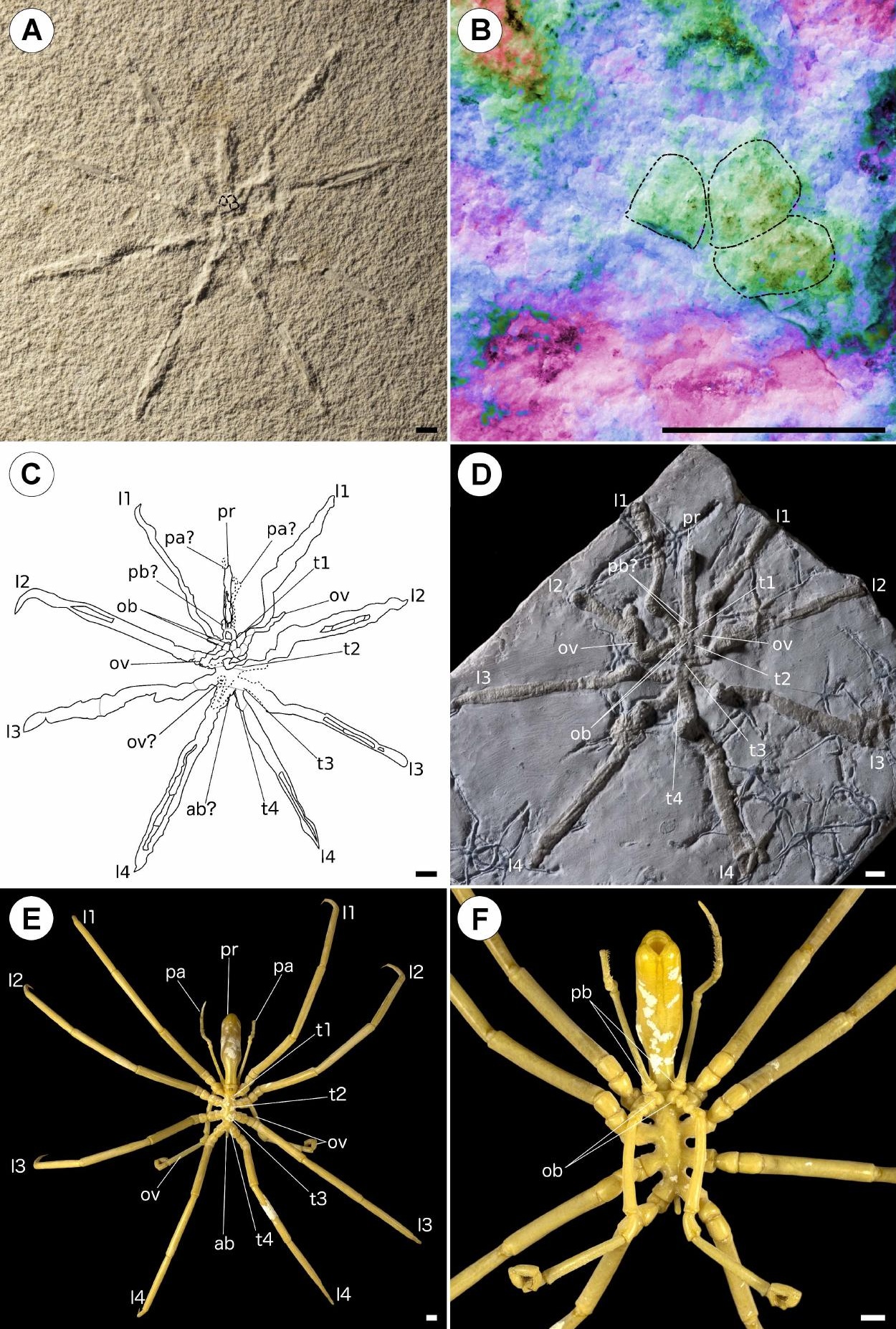



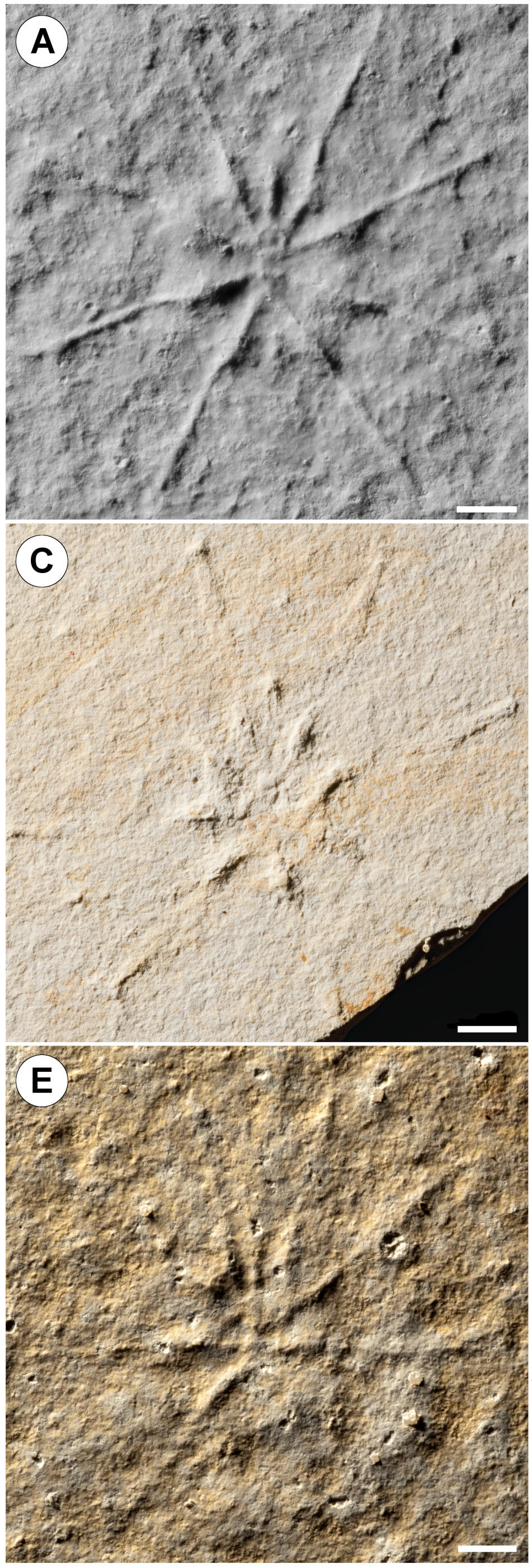
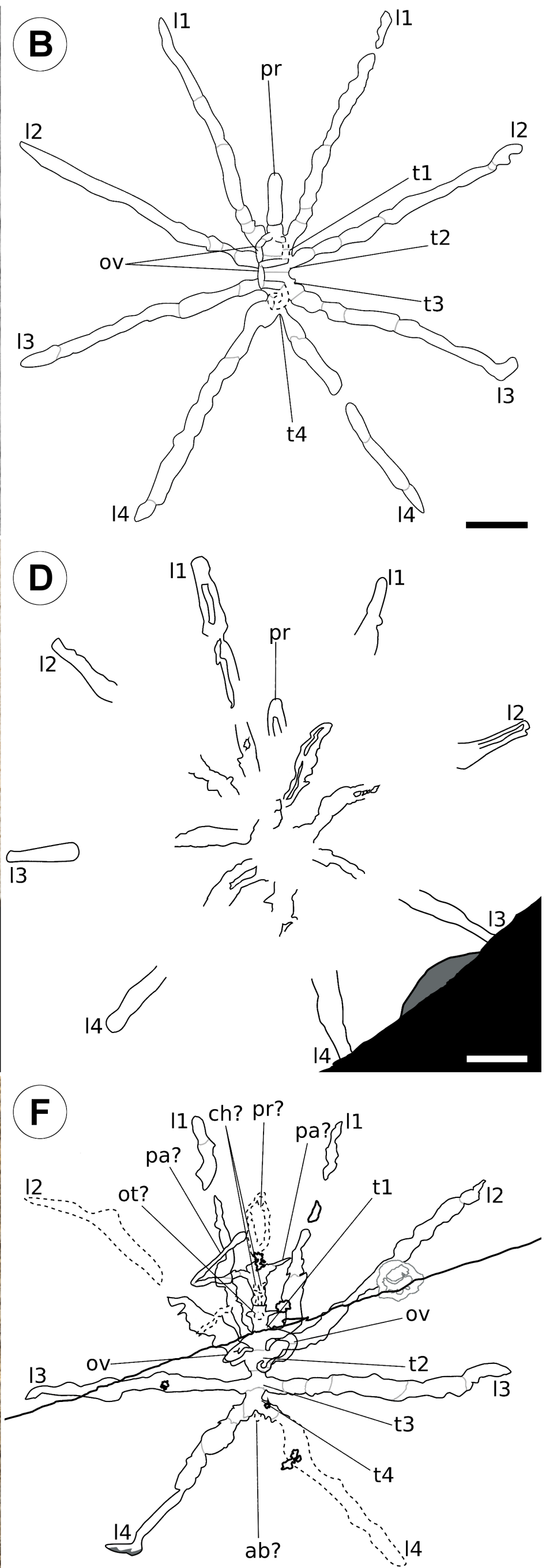


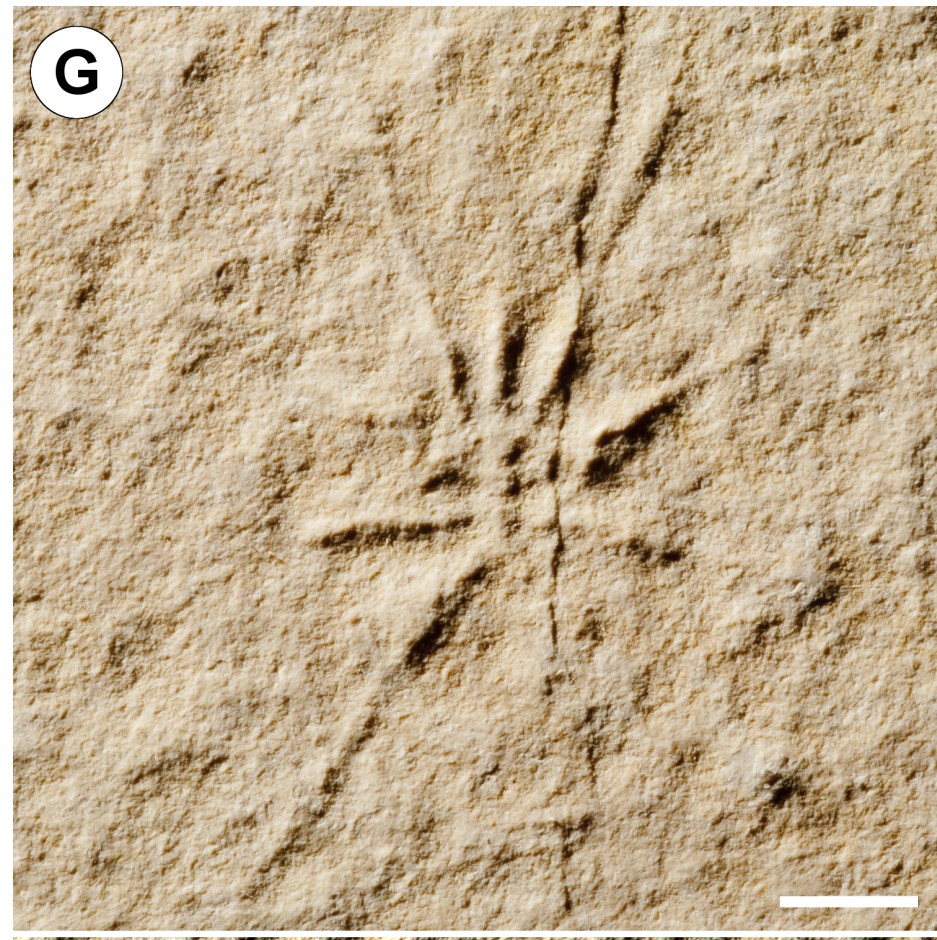

(H)

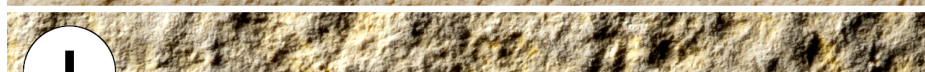

I 1 (1)

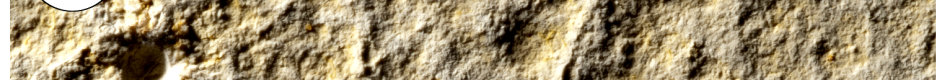

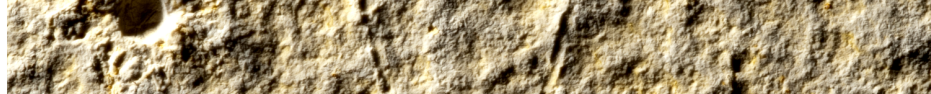

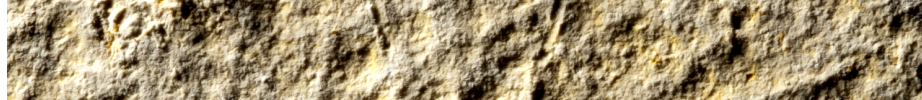

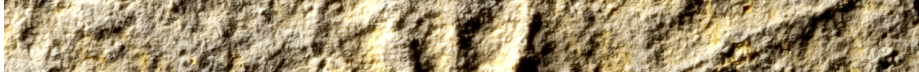
(1.

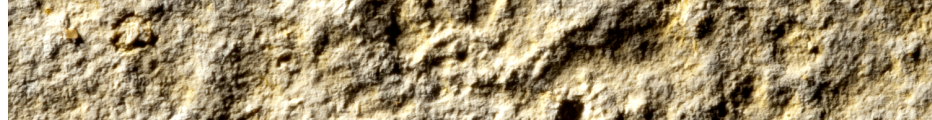

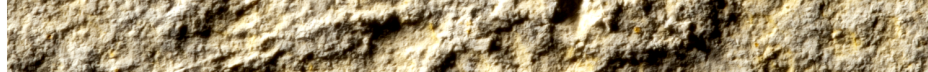
1.7. 7.

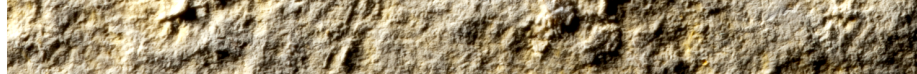

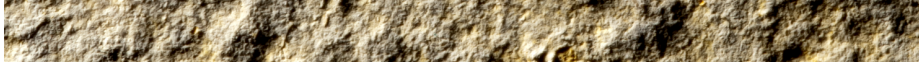

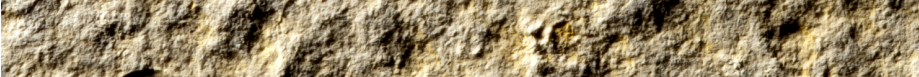

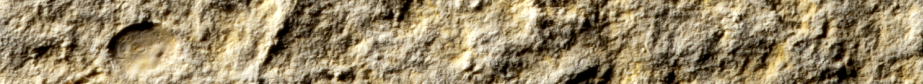

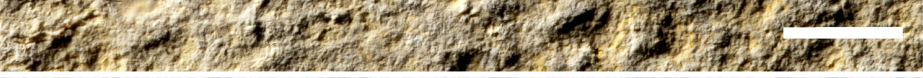

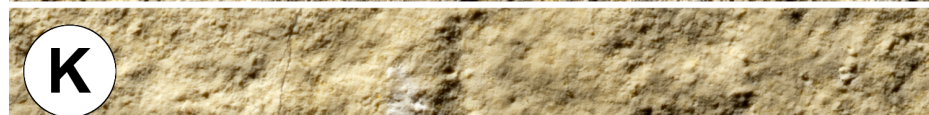

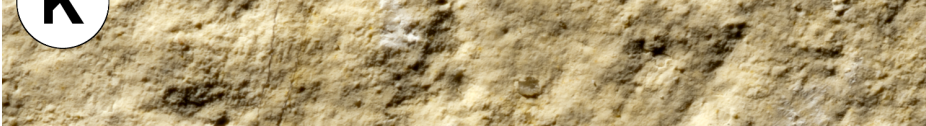
2.72n.

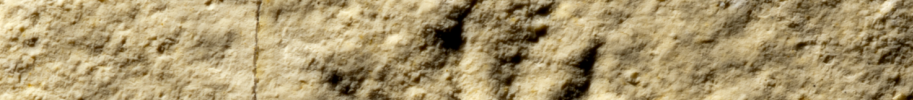

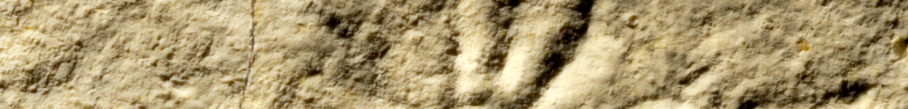

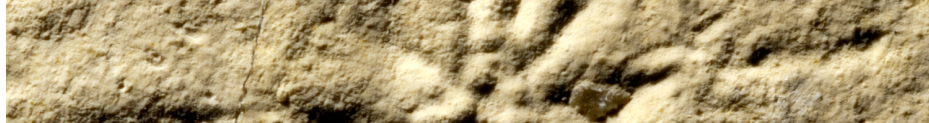
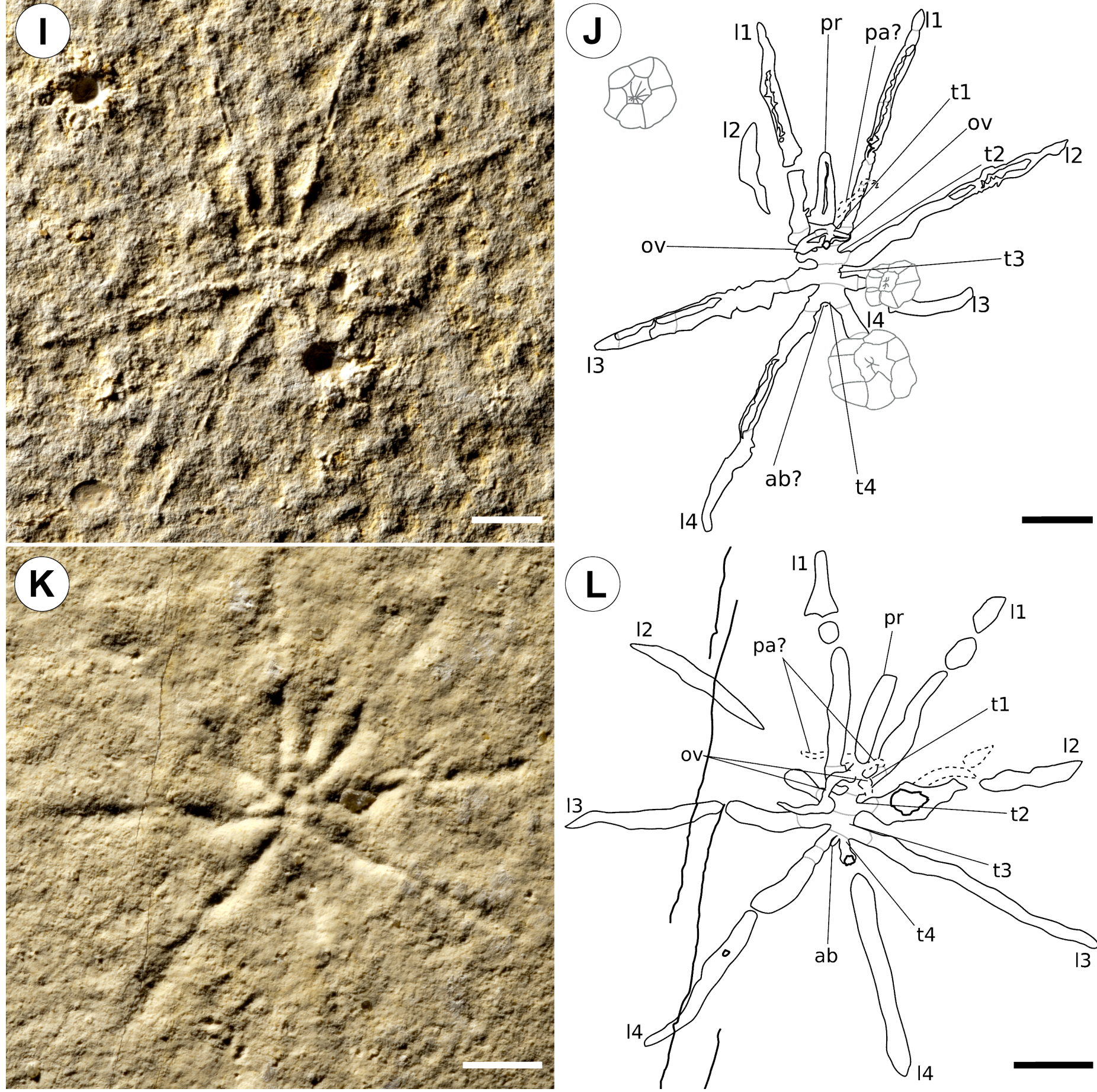

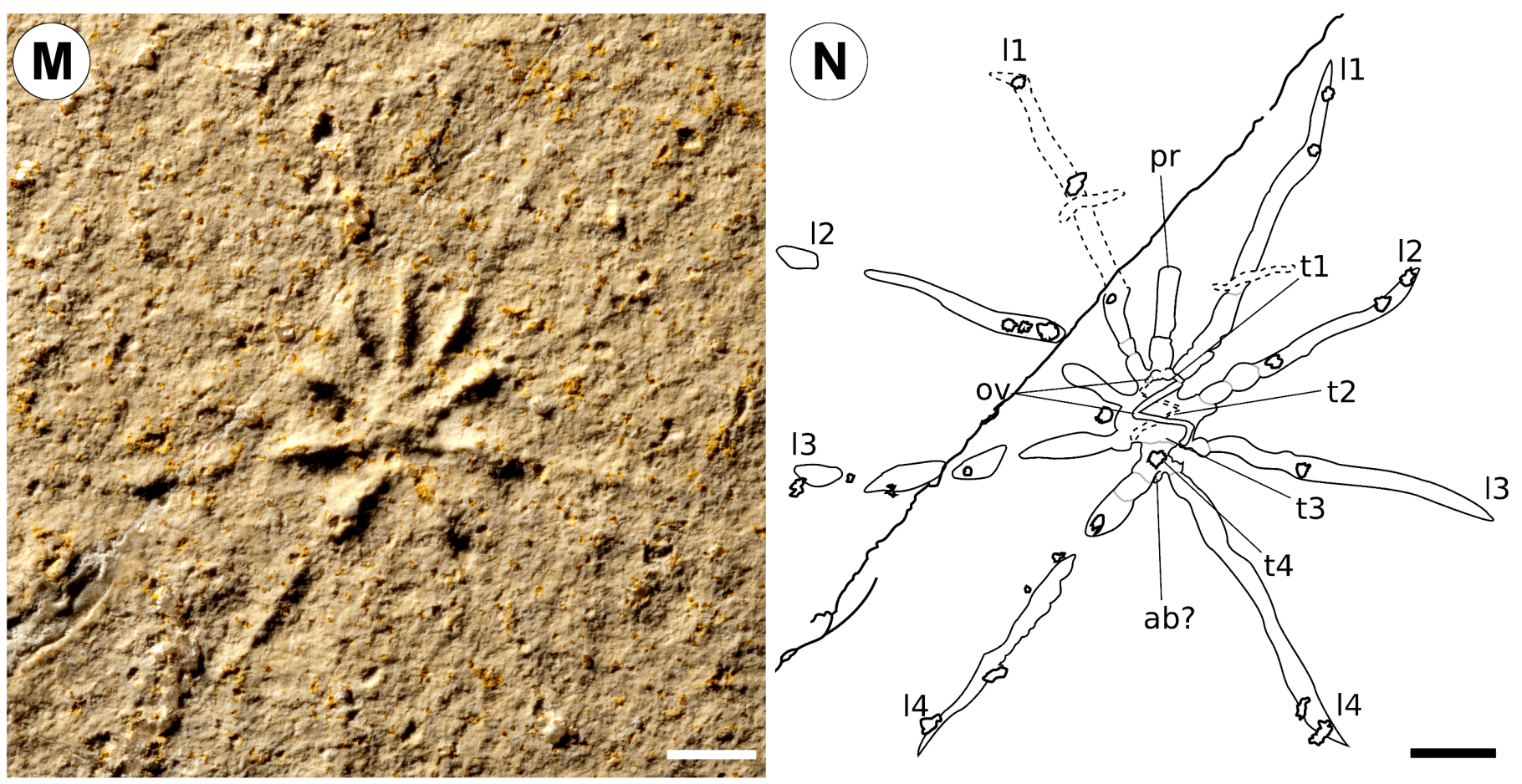

Figure S1. Undescribed sea spider fossils from Solnhofen pictured under natural light with enhanced contrast (A, C, E, G, I, K, M) and interpretative drawings (B, D, F, H, J, L, N): JME-SOS 2086b (A, B), JME-SOS 3652b (C, D), JME-SOS 3660 (E, F), JME-SOS 6290 (G, H), SMNS 70156 (I, J), SMNS 70209 (K, L), SMNS $70402(\mathrm{M}, \mathrm{N})$. The interpretative drawings represent distinctively unambiguous shape (plain black lines), ambiguous or unclear structures (dashed black lines) and tentatively placed articulations (plain grey lines). Grey roundish structures (F, J) are interpreted as comatulids. $a b$, abdomen; ch, chelifores; $l 1-l 4$, walking legs 1 to 4; ot, ocular tubercle; $o v$, ovigers; $p a$, palps; $p r$, proboscis; $t 1-t 4$, trunk segments 1 to 4 . All scale bars 5 $\mathrm{mm}$.

Remarks. The ovigers of JME-SOS-2086 (A, B) show similarities with the extant genus Endeis Philippi, 1843 , of which the antepenultimate podomere is long and bended. However, the exact number of podomeres and their structure cannot be assessed with certainty, as the granulometry does not provide clear information about articulation. An additional article, which does not exist in extant Endeis, may stand at the base of the ovigers. The possible absence of chelifores, which can be used to discriminate Endeidae Norman, 1908 from Phoxichilidiidae Sars, 1891 and Pallenopsidae Fry, 1978, cannot be verified because the specimen is in ventral view. 

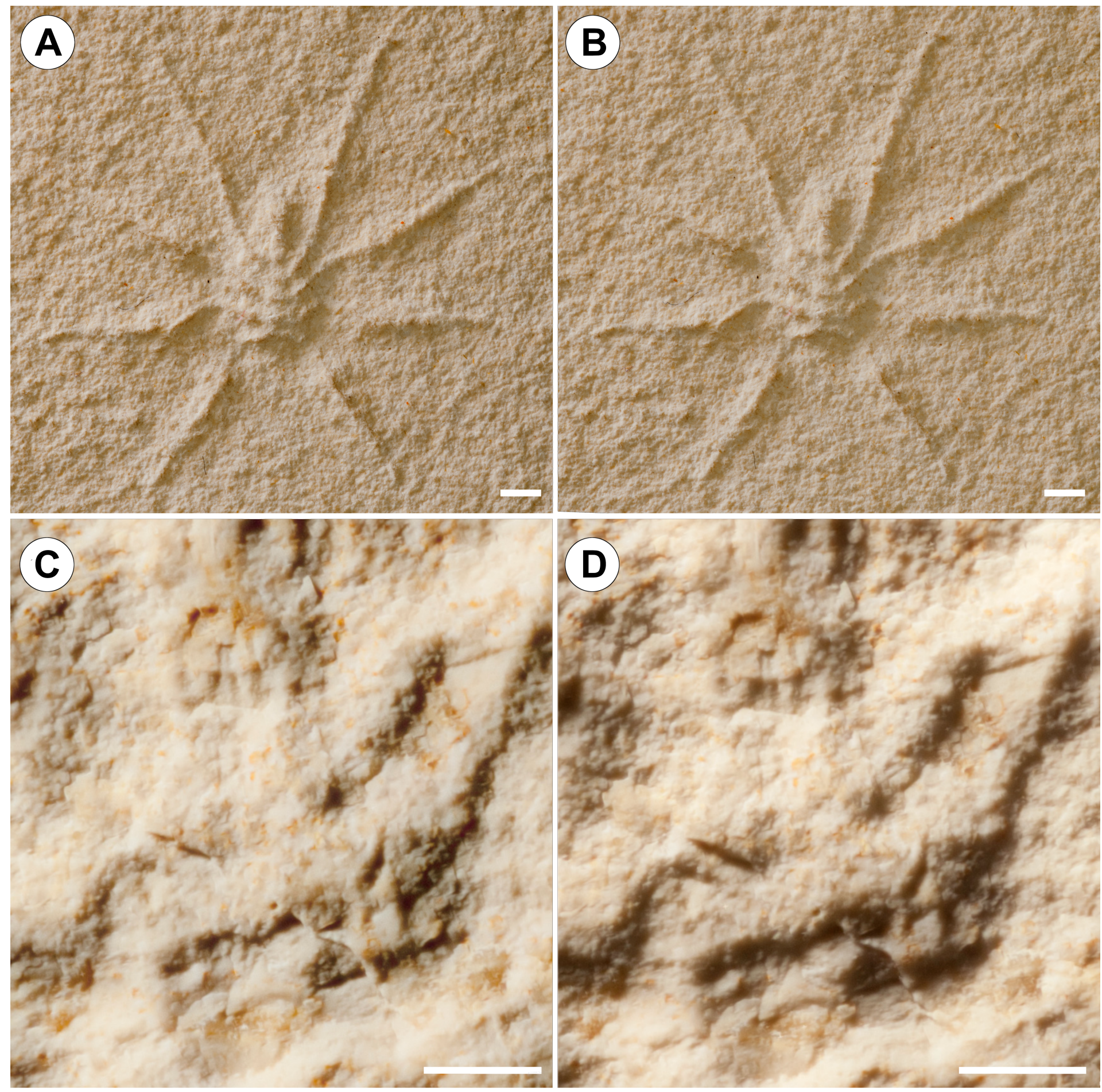

Figure S2. Stereo images of NHMUK-In-39751 (A, B) and JME-SOS-6291 (C, D), corresponding respectively to fig. $2 \mathrm{~B}$ and $3 \mathrm{~B}$, under natural light. Scale bars $2 \mathrm{~mm}$. 

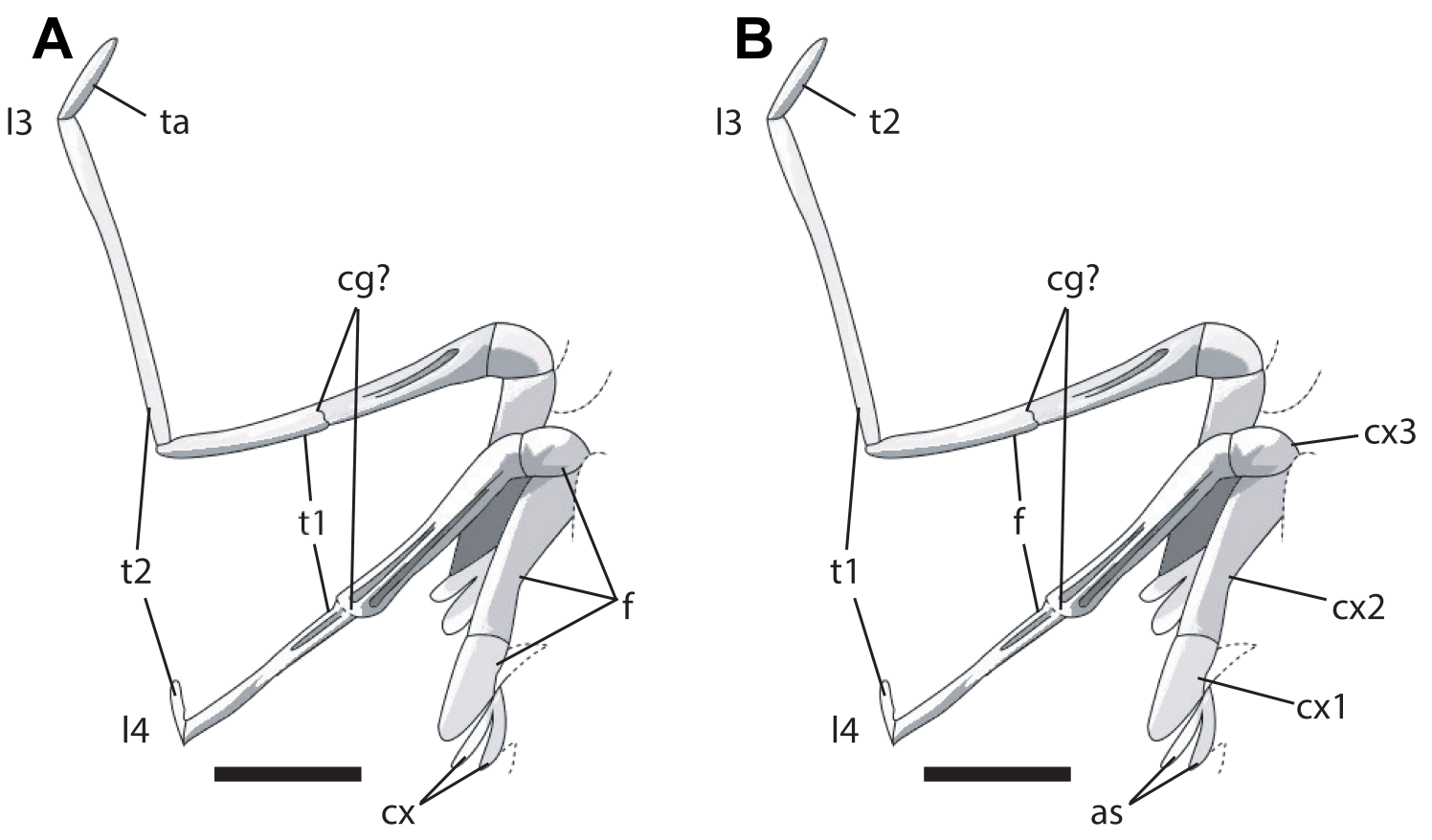

Figure S3. Interpretation of Flagellopantopus blocki Poschmann \& Dunlop, 2006 legs articles (A) in the original description and (B) in the present study. Legs are third (l3) and forth (l4) right legs of the type specimen PWL 2004/5024-LS. as, annular swelling of lateral processes; $c g$, cementary gland; $c x$ and $c x 1,2,3$, coxae not discriminated and coxa 1, 2, 3; f, femora; $t 1,2$, tibia 1, 2; ta, tarsus. Scale bars: 5 mm. Reference: Poschmann, M., \& Dunlop, J. A. (2006). A new sea spider (Arthropoda: Pycnogonida) with a flagelliform telson from the Lower Devonian Hunsrück Slate, Germany. Palaeontology, 49(5), 983-989. 